\begin{tabular}{|c|c|}
\hline & $\begin{array}{l}\text { International Journal of Trend in Scientific } \\
\text { Research and Development (IJTSRD) }\end{array}$ \\
\hline 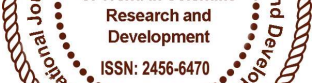 & International Open Access Journal \\
\hline 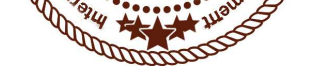 & ISSN No: 2456 - 6470 | www.ijtsrd.com | Volume - 2 | Issue - 2 \\
\hline
\end{tabular}

\title{
Strength and Durability of High Strength Fibre Reinforced Self Compacting Concrete with Nano Silica
}

\author{
M. Iyappan \\ Research Scholar, Department of Civil Engineering \\ Anna University, Guindy, Tamil Nadu, India
}

\author{
Dr. K. C. Pazhani \\ Associate Professor, Division of Structural \\ Engineering, Anna University, Guindy \\ Tamil Nadu, India
}

\section{ABSTRACT}

Conventional concrete used in building and civil engineering applications requires compaction to achieve strength, durability and homogeneity. The typical method of compaction, vibration, generates delays and additional costs in projects and moreover is a health hazard in and around construction sites. Self-Compacting Concrete is a highly flow able, stable concrete which flows readily into place, filling formwork without any consolidation and without undergoing any significant segregation. In the present experimental investigation the glass Fibres are added in different proportion $(0 \%, 0.5 \%, 0.75 \%, 1 \%)$ to total volume of cement and $4 \%$ of nano silica is constantly added in all mix of SCC \& to study the fresh and harden properties such as workability, compressive, split tensile flexural strength and durability test (sulphate resistance) on M50 grades concrete. Finally the test results are compared with conventional concrete. Based on the tests results, the use of $0.75 \%$ glass fibre with $4 \%$ of nano silica in self compacting concrete improves the quality of concreting \& produce comparatively better results in both strength as well as durability aspect.

Keywords: Self compacting concrete, Glass fibres, workability and harden properties of concrete, Durability using sulphate resistance test

\section{INTRODUCTION}

\subsection{GENERAL}

Self - compacting concrete (SCC) is a fluid mixture, which is suitable for placing in difficult conditions and also in congested reinforcement, without vibration. Development of self-compacting concrete (SCC) is a desirable achievement in the construction industry in order to overcome problems associated with cast-in-place concrete. Fibre Reinforced Concrete can be defined as a composite material consisting of mixtures of cement, mortar or concrete and discontinuous, discrete, uniformly dispersed suitable fibres. Continuous meshes, woven fabrics and long wires or rods are not considered to be discrete fibres. Fibres include steel fibres, glass fibres, synthetic fibres and natural fibres. Fibre is a small piece of reinforcing material possessing certain characteristics properties. The fibre is often described by a convenient parameter called aspect ratio. The aspect ratio of the fibre is the ratio of its length to its diameter. Typical aspect ratio ranges from 30 to 150 .

Steel fibres are used as a fibre reinforcing material in concrete to study its effects on the compressive, crushing, flexural strength and cracking control to economize concrete Fibre reinforced concrete has started finding its place in many areas of civil infrastructure applications especially where the need for repairing, increased durability arises. Self compacting fibre reinforced concrete is used in civil structures where corrosion is to be avoided at the maximum. Self compacting Fibre reinforced concrete is better suited to minimize cavitations/erosion damage in structures such as sluice-ways, 
navigational locks and bridge piers where high velocity flows are encountered. A substantial weight saving can be realized using relatively thin glass fibre sections having the equivalent strength of thicker plain concrete sections. When used in bridges it helps to avoid catastrophic failures. In the quake prone areas the use of fibre reinforced concrete would certainly minimize the human casualties. Glass Fibres reduce internal forces by blocking microscopic cracks from forming within the concrete.

\subsection{SCOPE}

Glass Fibres are usually used in concrete for the following reasons

i. To control cracking due to both plastic shrinkage and drying shrinkage.

ii. They also reduce the permeability of concrete and thus reduce bleeding of water.

iii. Some types of fibres also produce greater impact, abrasion and shatter resistance in concrete.

The fineness of the fibres allows them to reinforce the mortar fraction of the concrete, delaying crack formation and propagation. This fineness also inhibits bleeding in the concrete, thereby reducing permeability and improving the surface characteristics of the hardened surface

\subsection{OBJECTIVES}

To study the properties of glass fibre and nano silica

$>$ To study the harden properties of concrete, in which the glass fibres are added in different proportion to total weight of cement $(0 \%, 0.5 \%, 0.75 \%, 1 \%)$ and $4 \%$ of nano silica is used constantly in all mix of concrete, then the following test are to be conducted.

* Compressive Strength of concrete

- Flexural Strength of concrete

- Split tensile test of concrete

Compare the test results with Conventional self compacting concrete

\subsection{LITERATURE REVIEW}

V. M. Sounthararajan et al. (2013), Glass fibres in concrete improves the matrix densification, refinement of microstructure, reduction of voids, minimize cracking due to stresses, and enhance durability to reinforcement corrosion, sulphate attack, and alkali-silica expansion.
R.Gowri (2013), Glass wool fibre is added to the concrete to increase the strength as compared to the conventional concrete at lower cost.

K. vamshi Krishna(2014), the addition of alkaline resistant fibers improved the tensile and flexural strengths significantly. Compressive strength is marginally improved compared to the tensile and flexural strengths.

H S Jadhav et al.(2011) In this paper, a study has done on high performance concrete for the joined impact of silica fume and fly ash on the strength characteristics of concretes. They have worked on M80 grade concrete with water by cement proportion of 0.3 and have utilised super plasticizer at a constant value to achieve slump in the range. The main area of study in this paper is compressive strength characteristics. About 23 different concrete mixtures with different cement replacement levels of silica fume and fly ash were casted and tested. The analysis concluded that $8.39 \%$ greater compressive strength has been got with fly ash at $15 \%$ and silica fume at $10 \%$ both combined which was the optimum compared with the controlled concrete.

Girish.S et. al. (2012) The experimental study on silica fume and fly ash to know the maximum percentage replacement to cement is done. The study is done on M20 grade concrete for fresh and hardened properties. Silica fume is introduced into concrete at a increasing replacement levels of $2.5 \%$ upto $10 \%$ and fly ash at a increasing replacement levels of $10 \%$ from $0 \%$ upto $100 \%$. Compression, split tensile strength and acid resistivity test is done on the blended concrete. The study concluded that cement with replacement of $30 \%$ fly ash and $7.5 \%$ silica fume can be used.

Dilip Kumar Singha Roy et. al. (2012)In their study silica fume has used as fractional substitute to binder. They have showed that silica fume can be utilized to produce medium/low strength concretes as this silica fume adopts lesser water by cement fraction and involves in stronger bonding between the particles due to better hydration of cement particles. From the investigation they have concluded that a optimum compression strength value was noted at $10 \%$ cement replacement with silica fume and these noted values were greater than that those of normal concrete. Even split and flexure strength were greater at $10 \%$ 
substitution of bottom ash level than that of control concrete.

\section{PROPERTIES OF MATERIALS}

\subsection{ORDINARY PORTLAND CEMENT}

Table 2.1:Properties of Cement

\begin{tabular}{|l|l|l|}
\hline S. No. & Property Of Cement & Values \\
\hline 1 & Fineness Of Cement & $7.5 \%$ \\
\hline 2 & Grade Of Cement & 53 \\
\hline 3 & Specific Gravity & 3.1 \\
\hline 4 & Initial Setting time & 28 minute \\
\hline 5 & Final Setting Time & 600 minute \\
\hline
\end{tabular}

\subsection{FINE AGGREGATE}

The fine aggregate used is natural sand. The sand is sieved to remove all pebbles. The sieve size used is $4.75 \mathrm{~mm}$. The grading should be uniform throughout the work. The moisture content or absorption characteristics must be closely monitored as quality of SCC will be sensitive to such changes. specific gravity and fineness modulus are 2.5 and 2.65

\subsection{COARSE AGGREGATE}

The maximum size of aggregate is generally limited to $20 \mathrm{~mm}$. The aggregate serves as reinforcement to add strength to the overall composition. Aggregate are formed due to natural disintegration of rock, hence they derived many of their properties from the parent rock. These properties are chemical and mineral composition, specific gravity, hardness strength, physical and chemical stability. Among the various properties of aggregate, the important ones for SCC are the shape and gradation. The specific gravity of coarse aggregate is 2.7

\subsection{NANO SILICA}

The concrete mixtures investigated in this study were prepared with Portland cement type II, portable water and conplast SP430 and nano silica. The specific gravity of nano silica is 1.03 , and they are silica particles with a maximum size of $10 \mathrm{~nm}$, . In addition, nano silica is a water emulsion with $50 \%$ of dry solid and $\mathrm{PH}$ of 10 .. The control mix which was exclude of nano silica.

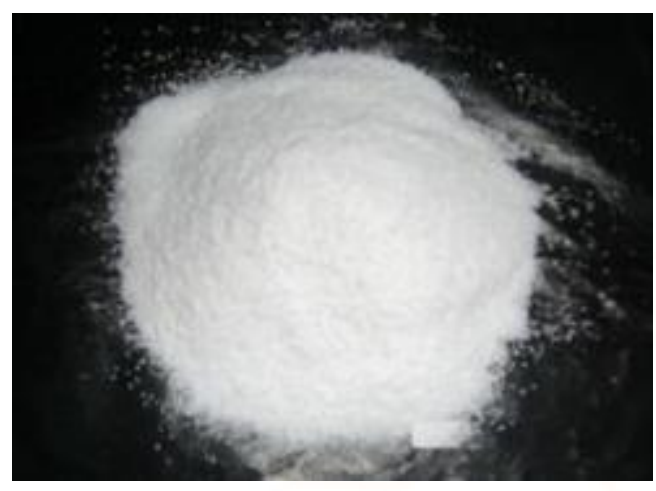

Fig 2.1: Nano silica

\subsection{GLASS FIBERS}

The glass fibers used in concrete suppressed the localization of micro cracks in to macro cracks hence tensile strength increase. It improves durability of concrete by increasing the strength of concrete. The Glass Fibers are of Cem-FIL Anti - Crack HD with modulus of elasticity $72 \mathrm{GPa}$, Filament diameter 14 microns. Specific Gravity is 2.68, length $12 \mathrm{~mm}$ and having the aspect ratio of 857.1 . The number of fibers per $1 \mathrm{~kg}$ is 212 million.

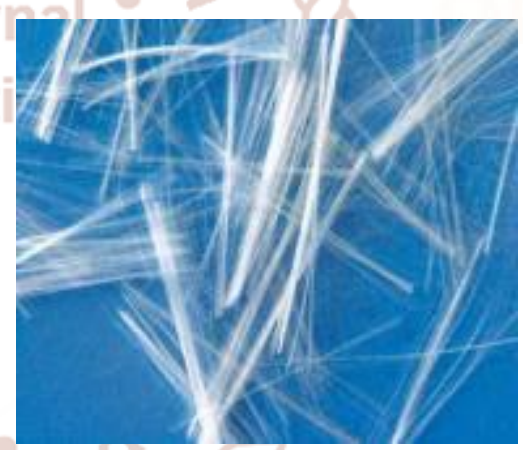

Fig 2.1: Glass Fibres

Table 2.2 : Properties of Glass Fibers

\begin{tabular}{|l|l|}
\hline Physical Properties & Value \\
\hline Length & $12 \mathrm{~mm}$ \\
\hline Aspect Ratio ( $1 / \mathrm{d})$ & 58 \\
\hline Specific gravity & 2.68 \\
\hline Softening Point & $3.6 \%$ \\
\hline Moisture & $0.3 \% \mathrm{max}$ \\
\hline Electrical Conductivity & Very Low \\
\hline Chemical Resistance & Very High \\
\hline Tensile Strength & $1700 \mathrm{MPa}$ \\
\hline
\end{tabular}

\subsection{SUPER PLASTICIZERS}

Plasticizers are additives that increase the plasticity or fluidity of the material to which they are added; these include plastics, cement, concrete, wallboard, and clay. Although the same compounds are often used for both plastics and concretes the 
desired effect is slightly different. Plasticizers for concrete increase the workability of the wet mix, or reduce the water required to achieve the desired workability, and are usually not intended to affect the properties of the final product after it hardens.

GLENIUM B233 is an admixture of a new generation based on modified polycarboxylic ether. The product has been primarily developed for applications in HPC where the highest durability and performance is required. GLENIUM B233 is free of chloride and low alkali. It is compatible with all types of cements. Advantages of super plasticizer are:

- Elimination of vibration and reduced labour cost in placing

- Marked increase in early \& ultimate strengths

- Higher E modulus

- Improved adhesion to reinforcing and stressing steel

- Better resistance to carbonation and other aggressive atmospheric conditions

- Lower permeability - increased durability

- Reduced shrinkage and creep

Traditional superplasticisers based on melamine and naphthalene sulphonates are polymers which are absorbed by the cement granules. They wrap around the granules surface areas at the very early stage of the concrete mixing process. The sulphonic groups of the polymer chains increase the negative charge of the cement particle surface and disperse these particles by electrical repulsion. This electrostatic mechanism causes the cement paste to disperse and has the positive consequence of requiring less mixing water to obtain a given concrete workability.

\section{FRESH AND HARDEN PROPERTIES OF CONCRETE}

\subsection{PROPORTION}

ACI Mix Design was used to achieve a mix with a compressive strength of 50Mpa.The water Cement Ratio 0.32 and the proportion of cement: fine Aggregate: Coarse Aggregate for the mix is 1:2.05:2.3 considered in this study.

\subsection{TEST ON FRESH CONCRETE}

Table 3.1 Workability test on self compacting concrete

\begin{tabular}{|c|c|c|c|c|c|}
\hline SI.No & $\begin{array}{l}\% \text { of Glass } \\
\text { Fibr with } \\
4 \% \text { Nano } \\
\text { silica }\end{array}$ & 高 & 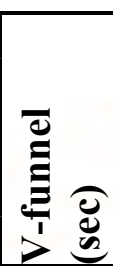 & $\begin{array}{l}\text { L-box } \\
\text { Test } \\
(\text { h2/h1) }\end{array}$ & 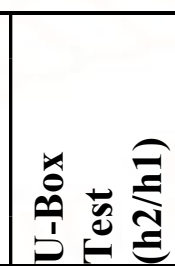 \\
\hline 1. & 0 & 790 & 9 & 0.95 & 28 \\
\hline 2. & 0.5 & 787 & 10 & 0.94 & 27.5 \\
\hline 3. & 0.75 & 783 & 10 & 0.93 & 27 \\
\hline 4. & 11 & 780 & 11 & 0.92 & 26 \\
\hline
\end{tabular}

\subsection{TEST ON HARDEN CONCRETE \\ 3.3.1 Compressive Strength}

This tests were carried out in accordance with IS 5161999 standards conducted on concrete specimen size $150 \mathrm{~mm} \times 150 \mathrm{~mm} \times 150 \mathrm{~mm}$. The specimens which are submerged in clean fresh water is taken out after 7 days, 14 days and 28 days for testing and kept in dry place so that the water is drained well to get better results. The specimen is loaded in the compression testing machine as shown in Figure. The load is gradually applied until it fails.

The compressive strength calculated by using formula $\mathrm{F}_{\mathrm{c}}=\mathrm{P} / \mathrm{A}$

Where,

$\mathrm{P}=$ ultimate load $(\mathrm{N})$

A $=$ loaded area

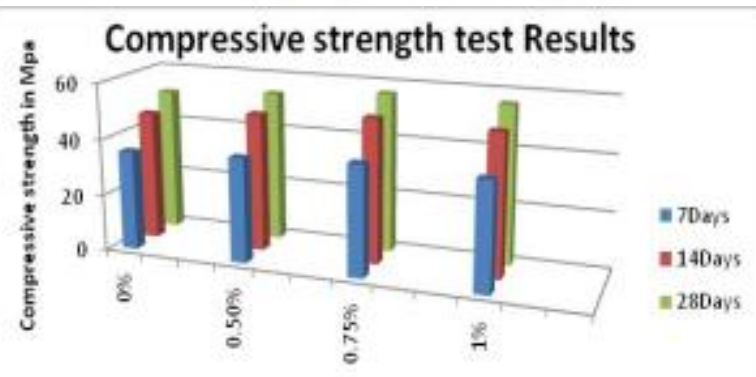

\%of glass fibre with $4 \%$ of Nano silica

Graph 3.1: Comparison of Compressive strength of concrete test results 
It shows that addition of Glass fibre about $0.75 \%$ with $4 \%$ nano silica in SCC, increase the compressive strength by $9 \%$ as compared with conventional concrete. Nano silica which are having large surface area and glass fibres gives more bond between particles are helps to improve the compressive strength

\subsubsection{Split tensile strength}

This tests were carried out in accordance with IS 5161999 standards conducted on concrete cylinders of $150 \mathrm{~mm}$ diameter and $300 \mathrm{~mm}$ length. The cylindrical specimen are placed horizontally between the loading surfaces of a compression testing machine and the load is applied until failure of the cylinder along the vertical diameter. The failure load is noted. The splitting tensile strength is calculated using the formula.

$$
\mathrm{F}_{\mathrm{t}}=2 \mathrm{P} / \pi \mathrm{ld}
$$

Where,

$\mathrm{P}$ is the compressive load at which the cylinder will fail

1 is the length of cylinder $-300 \mathrm{~mm}$

$\mathrm{d}$ is the diameter $-150 \mathrm{~mm}$

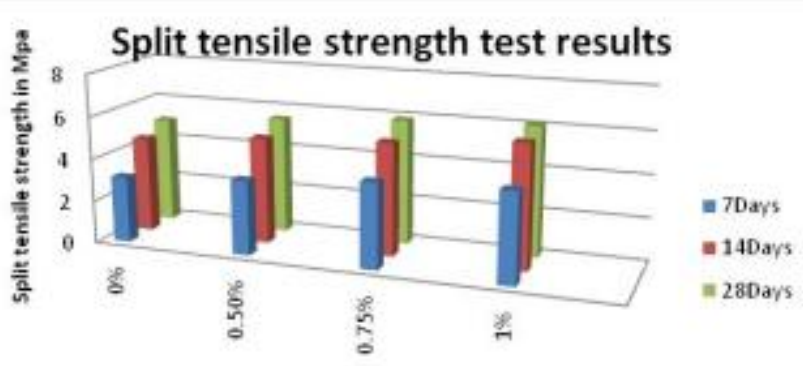

\% of Glass fibre with $4 \%$ of Nano silica

Graph 3.2 : Split tensile strength of concrete test results

It shows that addition of Glass fibre about $0.75 \%$ with $4 \%$ nano silica in SCC , increase the split tensile strength by $25 \%$ as compared with conventional concrete

\subsubsection{Flexural Strength}

Determination of flexural strength is essential to estimate the loads at which concrete members may crack. The bearing surface of the supporting and loading rollers were wiped clean, and any loose sand or other material were removed from the surface of the specimen where they are to make contact with the rollers. The specimen was then placed in the machine in such a manner that the load was applied to the uppermost surface as cast in the mould, along two lines spaced $13.3 \mathrm{~cm}$ apart. The axis of the specimen was carefully aligned with the axis of the loading devise. No packing was used between the bearing surface of the specimen and the rollers. The load was applied without shock and increasing continuously. Then ' $a$ ' is the distance between the line of fracture and the nearer support. The line of fracture measured on the centre line of the tensile side of the specimen.

Size of beam $=500 \times 100 \times 100 \mathrm{~mm}$

\section{$\mathrm{f}_{\mathrm{cr}}=(\mathrm{Px} \ell) /\left(\mathrm{bxd}^{2}\right)$}

Where,

$b=$ ensured width in the specimen

$\mathrm{d}=$ measured depth in $\mathrm{cm}$ of the specimen at the point of failure

$\ell=$ length in $\mathrm{cm}$ of the span on which the specimen was supported

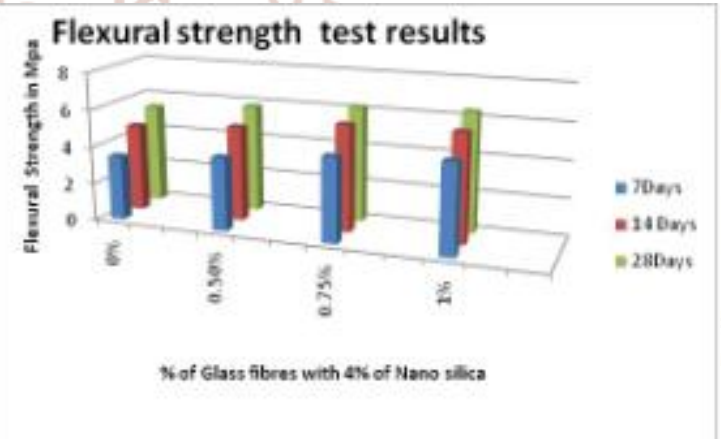

Geraph 3.3: Flexural strength of concrete test results

It shows that addition of Glass fibre about $0.75 \%$ with $4 \%$ nano silica in SCC, increase the Flexural strength by $35 \%$ as compared with conventional concrete

\section{DURABILITY STUDY}

Durability test were performed for concrete with $0.75 \%$ of glass Fibre. Because of these proportion of concrete only gives very higher compressive, split tensile, Flexural Strength compared with conventional concrete.

\subsection{SULPHATE ATTACK}

Sulphates attack only certain compounds in cement. They react with hydrated calcium aluminates to form ettringite and with free calcium ions to form gypsum. These compounds have greater volumes than the reactants and cause the concrete to expand. This expansion leads to cracking with an irregular pattern This gives easier access to sulphates for further penetration. The process continues till the complete 
disintegration and destruction of concrete. The cracking and disintegration depends on

- Exposure condition, i.e., the amount of aggressive substance

- Permeability of concrete

\section{Susceptibility of concrete (type of cement}

An experimental study was undertaken to evaluate the relative chemical resistance of recycled concrete contains $4 \%$ of steel fibre and $3 \%$ of nano silica to the following solution; $1 \% \mathrm{H}_{2} \mathrm{SO}_{4}, 1 \% \mathrm{HCl}$ and $5 \%$ ammonium sulphate. Sulphuric acid and hydrochloric acid were used for acid resistance study and sulphate resistance was determined by ammonium sulphate. Time taken to register $25 \%$ weight loss by fully submerged concrete specimens was used as a criterion for failure. In the present study $150 \mathrm{~mm}$ cubes were used for testing and the concrete specimens were undergoes alternate wetting and drying process for a 15 days interval. The figure shows the specimen immersed in chemical solutions. The weight loss of the specimens determined as follows:

$$
\text { Weightloss }(\%)=\frac{(\mathbf{W} 1-\mathbf{W} 2)}{\mathbf{W 1}} \times 100
$$

Where ' $\mathrm{W} 1$ ' is the weight of the specimens before immersion and ' $\mathrm{W} 2$ ' is the weight of cleaned specimens after immersion.

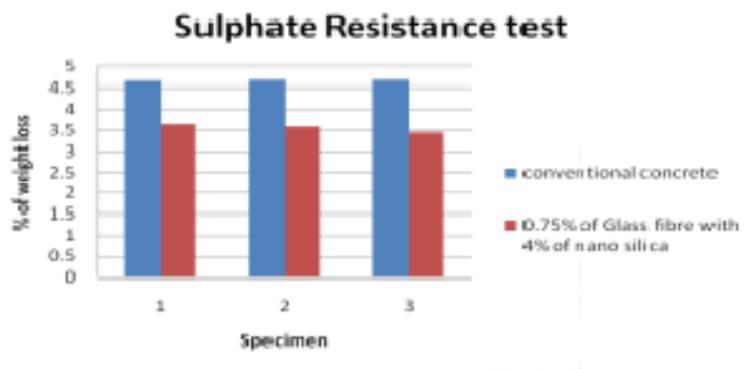

Graph 4.1 : Comparison of Sulphate resistance test results

\section{CONCLUSION}

The following conclusions are arrived based on experimental investigation.

It has been observed that the workability of concrete decreases with the addition of glass Fibres. But this difficulty can be overcome by using super-plasticizers.

$>$ It has been also observed that there is gradual increase in early strength such as Compressive strength (9\%), Split tensile strength $(25 \%)$ and sFlexural strength $(35 \%)$ of self compacting glass
Fibre Reinforced Concrete made of $0.75 \%$ of glass fibre \& $4 \%$ of Nano silica as compared to Plain Concrete.

The durability test conducted on $0.75 \%$ glass fibre with $4 \%$ of nano silica addition in SCC shows that more acid resistance compared with conventional concrete

\section{REFERENCES}

1 Sekar T. (1999), 'Role of Fibre in Concrete', Proceeding of the National Symposium on Recent Trends in Concrete Technology, Vol. 1, pp. 225228.

2 Sangeetha P., and Sumathi R. (2010), 'Behaviour of Glass Fiber Wrapped Concrete Columns Under Uniaxial Compression', International Journal of Advanced Engineering Technology, Vol. 1, pp. 74-83.

3 Chandramouli G. (2010), 'Study on Strength and Durability Characteristics of Glass Fibre Concrete', International Journal of Mechanics and Solids, Vol. 5, pp. 15-26.

4 H S Jadhav and R R Chavarekar "Role of Fly Ash and Silica Fume on Compressive Strength Characteristics of High Performance Concrete", IJSCER Vol. 2, No. 1, Feb 2013

5 Girish.S, Karisiddappa, Amar.R "Experimental Study to Obtain Optimum Replacement Percentage of Flyash and Addition of Silica Fume in Blended Concrete", International Journal of Research (IJR) Vol-1, Issue-7, Aug 2014

6 P. Bhuvaneshwariand R. Murali, "Strength Characteristics of Glass Fiber on Bottom Ash Based Concrete", International Journal of Science, Environment and Technology, Vol. 2, No 1, pp. 90-102, 2013.

7 Deshmukh S.H., Bursary J. P, Zoned A. M. "Effect of Glass Fibers on Ordinary Portland cement Concrete", IOSR Journal of Engineering, June. 2012, Vol. 2(6) pp. 1308-1312.

8 Okumura. H, Ozawa. K. Ouchi. M. (2000), "Self Compacting Concrete", Structural concrete, No.1.

9 Hajime Okamura and Masahiro Ouchi (2003) "Self-Compacting Concrete", Journal of Advanced Concrete Technology, Japan Concrete Institute, Vol. 1,pp. 5-15.

10 IS: 9103: 1999, Indian Standard Code for Super plasticizer. 